\title{
A Mina-Escola de Santa Luzia-PB: um laboratório didático para estudantes de Mineração/Geologia
}

\author{
The School Mine of Santa Luzia-PB: a didactical laboratory for Mining/Geology students \\ Lauro Cézar Montefalco de LiRa Santos ${ }^{1,2}$; lure Borges de Moura Aquino $0^{1,3}$; Barthira A. Nunes ${ }^{1,4}$ \\ 1-Unid. Acad. de Mineração e Geologia. Univ. Fed. de Campina Grande, Av. Aprígio Veloso 882, Bodocongó. 58109.970 Campina Grande, PB. \\ 2-lauromontefalco@gmaill.com \\ 3-lurebmaquino@gmail.com \\ 4-barthiraalmeida@gmail.com
}

ABSTRACT: The Santa Luzia School Mine School Mine is a didactical resource located in the vicinity of Santa Luzia Town, Paraíba. It is a laboratory for mining studies, due to its facilities, including underground gallery, offices, accommodation and mining machinery, as well as a mineral processing plant. In addition, it has a great potential for geology didactical activities, which has not yet been used. Its access gallery is composed of $200 \mathrm{~m}$ of underground mining shaft, which was recently mapped in detail. It exhibits a wide lithological and mineralogical content, covering pegmatites, migmatites, mylonites and skarns, besides ductile and brittle structures. Skarn lenses usually host scheelite crystals, which can be easily identified by mineral light and HCL reaction. The distribution of ore and sterile material, plus the variety of lithotypes and structures accredit the School Mine a perfect site for didactical activities in NE Brazil, including disciplines such as Economic Geology, Mineral Prospecting and Structural Geology.

\section{Introdução}

Trabalhos de campo e visitas técnicas fazem parte da rotina dos cursos técnicos e de graduação voltados para o setor mineral, tais como geologia e engenharia de minas. Entretanto, estas atividades requerem logística complexa e muitas vezes onerosa, além de elevado cuidado com a segurança, o que pode comprometer o pleno desenvolvimento da atividade didática.

No caso da maior parte da região Nordeste do Brasil, esta situação é ainda mais complexa, em função da escassez de mineradoras de grande porte, havendo necessidade de deslocamentos por longas distâncias.

Por outro lado, localmente os estados da Paraíba e Rio Grande do Norte, apresentam amplo potencial mineral, principalmente voltado à extração de minerais industriais e gemas, incluindo a famosa Turmalina Paraíba, extraída nas adjacências do município de São José da Batalha-PB. Tal potencial é conhecido desde as épocas das grandes guerras,

\section{Manuscrito}

Recebido: 15/07/2017

Corrigido: 22/08/2017

Aceito: 24/08/2017

Citation: Santos L.C.M.L., Aquino I.B.M., Nunes B.A. 2017. A MinaEscola de Santa Luzia-PB: um laboratório didático para estudantes de Mineração/Geologia.Terræ Didatica, 13(3):212-218. <http:// www.ige.unicamp.br/terraedidatica/>

Keywords: Field research, underground mining, Paraíba State. 
Com objetivo de criar um núcleo avançado para estudos de mineração cobrindo a cadeia geologia-lavra-beneficiamento no Nordeste do Brasil, o núcleo de professores fundadores do curso de Engenharia de Minas da então Universidade Federal da Paraíba (posteriormente desmembrada em Universidade Federal de Campina Grande), incluindo o atuante geólogo José Aderaldo Medeiros Ferreira, fundou a Mina-Escola na transição entre as décadas de 1970-1980, como um importante instrumento para o desenvolvimento da Pequena Mineração no Seridó Paraibano (ler Ferreira 2011 para histórico detalhado).

A Mina-Escola localiza-se nas proximidades do Município de Santa Luzia, estado da Paraíba, às margens da BR-230, cobrindo a ocorrência scheelitífera de Carnaubinha, estando hoje desativada e sob custódia da Universidade Federal de Campina Grande. Apesar do maquinário mineral parado, seu entorno e sua principal galeria de acesso e galerias de lavra, representam uma excelente oportunidade para realização de atividades básicas de geologia de mina: a) mapeamento litolótico/faciológico de galerias, b) mapeamento estrutural c) análise básica de qualidade de maciços rochosos, dentre outras.

Em reconhecimento da importância da Mina-Escola como instrumento didático único na região e que deve ser aberto ao público, sobretudo para estudantes de graduação/nível técnico em Engenharia de Minas e Geologia, este trabalho objetiva apresentar aspectos geológicos básicos desta mina, servindo como roteiro para professores e estudantes do setor, que desejem utilizá-la para trabalhos técnicos voltados para o ensino da mineração.

\section{Possibilidades metodológicas da Mina-Escola}

A área que cobre a mina-escola localiza-se a $120 \mathrm{~km}$ do município de Campina Grande-PB, abrangendo aproximadamente 12,5 hectares. Relatos dos trabalhadores que atuaram na Mina desde sua fundação dão conta que as atividades de lavra subterrânea ocorreram até 1987, enquanto que a usina de beneficiamento operou de forma contínua até o ano de 2004, apresentando, assim, requisitos suficientes para sua utilização em cursos técnicos e de nível superior voltados para o ramo da mineração. Nos anos recentes, ela tem funcionado como laboratório para visitas técnicas e aulas práticas de disciplinas dos cursos técnicos de Mineração e superior de Engenharia de Minas, especialmente dos estados da Paraíba e Rio Grande do Norte. A
Mina conta com uma estrutura básica, análoga a um empreendimento mineiro de pequeno porte: escritório, alojamento, refeitório, além de equipamentos para beneficiamento de minério e, normalmente, sua utilização tem sido voltada para disciplinas na área de tratamento de minérios e lavra de minas, especialmente subterrânea.

A ampla variedade litológica e estrutural, as galerias subterrâneas da Mina-Escola são um ótimo instrumento didático para cursos de graduação e técnicos em Geologia. Embora ainda não existam cursos de graduação em geologia no estado da Paraíba, a Mina-Escola pode e deve servir para universidades dos estados vizinhos, com possibilidade de atender às necessidades de aulas práticas das disciplinas de Geologia Econômica, Prospecção Mineral, Desenho Geológico, Geologia Estrutural, Geotécnica, Geomecânica, Geofísica terrestre entre outras. Podem ser agendadas visitas técnicas de forma simples com a Unidade Acadêmica de Mineração e Geologia da Universidade Federal de Campina Grande (UFCG). Especificamente para o presente trabalho, foram realizadas duas etapas de campo espaçadas, com duração de 2 dias cada. $\mathrm{O}$ trabalho durou em média $6 \mathrm{~h} / \mathrm{dia}$ e resultou em grande parte do esforço da terceira autora (para realização de trabalho de conclusão de curso), que contou com auxílio de 10 alunos das disciplinas Petrografia e Geomecânica. Este é considerado pelos professores orientadores, o limite máximo permitido por questões de segurança. Apesar de o empreendimento contar com alojamento, a recente dificuldade em manutenção torna desconfortável o pernoite. Uma possibilidade é pernoitar no município de Santa Luzia, que conta com boa estrutura e hotéis com qualidade razoável.

\section{Contexto geológico}

A Mina-Escola está localizada na porção sul da Sub-província Rio Grande do Norte (SRN), ocupando a parte Setentrional da Província Borborema, limitada respectivamente ao sul e norte pelos Lineamentos Patos e Senador Pompeu (Fig. 1; Brito Neves et al. 2000). Esta província corresponde à porção Pré-Cambriana do extremo Nordeste do Brasil, tendo se consolidado tectonicamente por meio da convergência dos blocos cratônicos São Francisco-Congo e São Luis-Oeste África durante a orogenia Brasiliana no Neoproterozoico (Almeida et al. 1981). Suas diversas sub-províncias, tem sido interpretadas como o resultado de episódios orogênicos e colisio- 


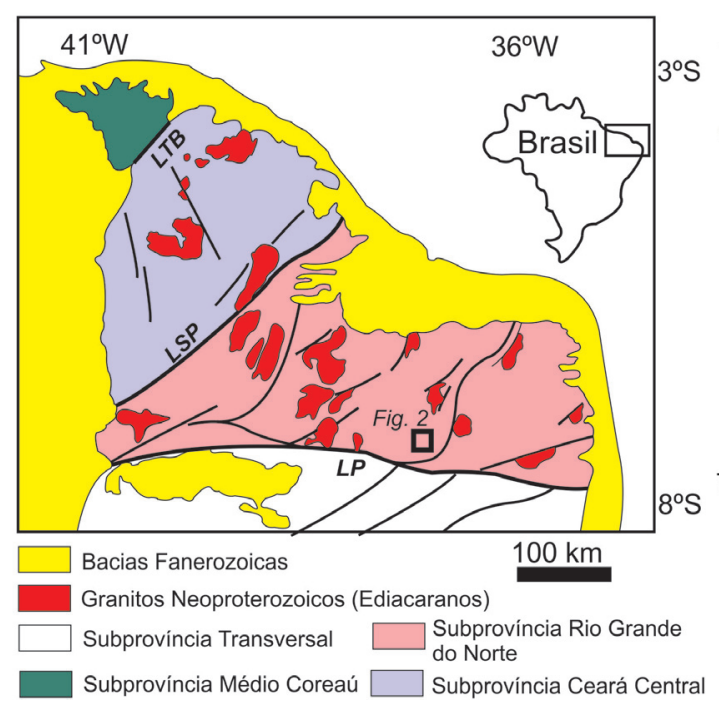

Figura 1. Porção Setentrional da Província Borborema: principais sub-províncias e localização da área que abrange a Mina Escola modificada de Brito Neves et al., (2000). LTB = Lineamento Transbrasiliano, $\mathrm{LSP}=$ Lineamento Senador Pompeu e LP = Lineamento Patos

nais amalgamando diversos blocos crustais ou terrenos tectono-estratigráficos (Santos et al. 2000; Santos e Medeiros 1999; Brito Neves et al. 2000)

A SRN é caracterizada por alternância entre faixas neoproterozoicas e terrenos paleoproterozoicos, além de possuir ocorrências pontuais de núcleos/complexos arqueanos e abundante plutonisno neoproterozoico-ediacarano, sendo cortada por ampla rede de zonas de cisalhamento de direção NNE-SSW com forte expressão geofísica. Em comparação com outras regiões da Província Borborema, sua porção sul é ainda caracterizada por numerosos depósitos e ocorrências minerais menores, sobretudo hospedados em rochas supracrustais da Faixa Seridó e em pegmatitos graníticos da Província Pegmatítica do Seridó (Santos et al. 2014 e referências ali contidas).

As adjacências da Mina-Escola estão encaixadas em rochas moderadamente à fortemente deformadas, influenciadas principalmente pelo efeito de uma trama de direção NE-SW, típica da porção sul da Faixa Seridó (Fig. 2). As rochas mais antigas do seu entorno são mapeadas como ortognaisses de composição granodiorítica a granítica além de migmatitos, que formam o embasamento paleoproterozoico do Terreno Rio Piranhas. Rochas mais recentes são metassedimentares, que englobam as

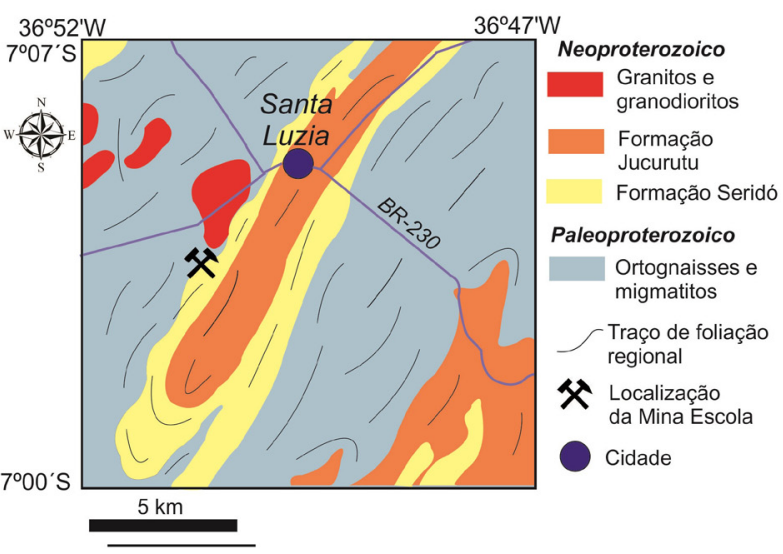

Figura 2. Mapa geológico das adjacências da Mina Escola, região de Santa Luzia-PB. Fonte: Autores

formações Seridó (xistos e paragnaisses compostos pela associação biotita \pm granada \pm sillimanita \pm cordierita, além de anfibolitos e esparsas ocorrências de mármores) e Jucurutu (paragnaisses, mármores, skarns e rochas calcissilicáticas) da Faixa Seridó, além de granitos e granodioritos que apresentam idade ediacarana (Santos et al. 2002). Boa parte das mineralizações metálicas da Província Borborema concentra-se ao longo desta faixa, incluindo ouro $(\mathrm{Au})$, wolfrâmio (W), molibdênio (Mo), bismuto (Bi), dentre outros metais (Santos et al. 2014).

\section{Mapeamento geológico da galeria de acesso}

Especificamente, a galeria subterrânea estudada localiza-se na porção sul da área delimitada para a Mina-Escola (Fig. 3). Por questões de segurança, foi mapeada apenas a galeria de acesso da mina, a qual compreende cerca de $200 \mathrm{~m}$ de extensão, tendo 2,5

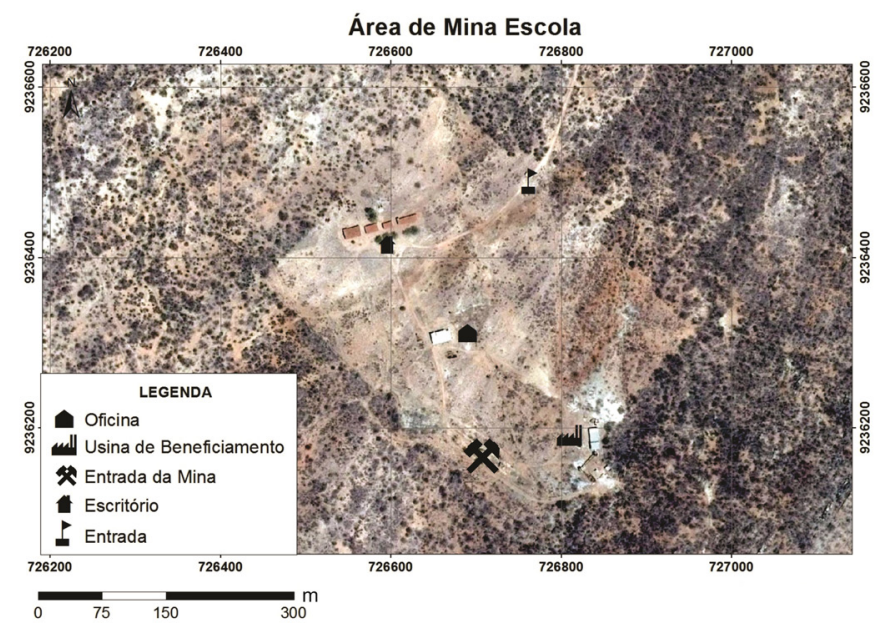

Figura 3. Mapa da área com a localização do maquinário disponível e localização da entrada da Mina escola. Datum utilizado: WGS84. Fonte: imagem retirada do Google Earth e posteriormente tratada 
de altura e $5 \mathrm{~m}$ de largura. As galerias de lavra são acessadas por shafts e/ou apresentam quantidade considerável de "chocos" (termo coloquial que refere-se a blocos instáveis dentro de uma galeria subterrânea),o que pode pôr em risco a integridade física dos estudantes. Neste sentido, as regiões consideradas inseguras encontram-se isoladas e o acesso por parte dos alunos é inteiramente restrito.

A galeria de acesso por outro

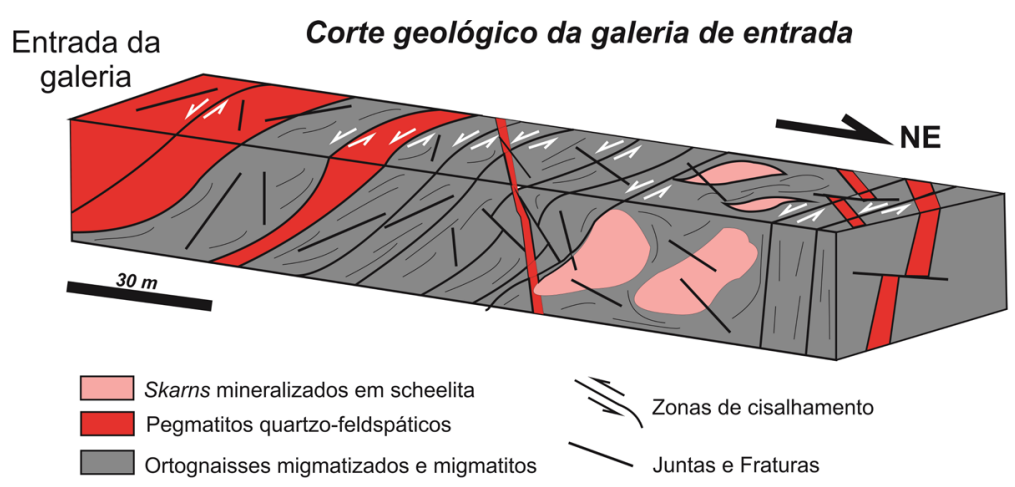

Figura 4. Bloco-diagrama 3D com os principais litotipos e estruturas mapeadas na Mina Escola, Santa Luzia-PB. Fonte: Autores lado, foi desenvolvida na direção NW-SE, perpendicular ao trend estrutural regional, preferencialmente NE-SW e N-S. Para efeitos didáticos, principalmente em relação às variações litológicas, a descrição da galeria é apresentada em 3 seções distintas; de 0-50m, de 50-150m e de 150$200 \mathrm{~m}$, as quais que respeitaram as variações litológicas e diferentes marcadores estruturais mapeados (Figuras 4 e 5).

O mapeamento de galeria foi feito a pé, com equipamento de campo bastante restrito em função das dimensões da galeria (2,5m de largura e $2,0 \mathrm{~m}$ de altura), da elevada temperatura e luminosidade inexistente (Fig. 6). A seção 1 abrange a entrada e a porção inicial da galeria. Esta área é caracterizada pela predominância de metros de pegmatitos quartzo-feldspáticos (Fig. 7a), intrusivos em gnaisses migmatíticos fortemente dobrados (Fig. 7b). Os pegmatitos são caracterizados por textura grossa com cristais de quartzo com dimensões superiores a $15 \mathrm{~cm}$, podendo possuir ainda turmalina euédrica e muscovita radial de forma disseminada.

Por outro lado, os gnaisses intercalados apresentam bandamento composicional vertical bem desenvolvido e por vezes fortemente dobrados, sendo caracterizados por bandas félsicas ricas em feldspato potássico, quartzo e biotita, enquanto que as porções máficas são dominadas por anfibólio esverdeado em um arranjo dominado 60-80 ${ }^{\circ}$ para $\mathrm{W}, \mathrm{NW}$ e $\mathrm{N}$, o que é compatível com a estruturação regional.

Próximo ao final desta seção, em torno de $40 \mathrm{~m}$ de extensão da galeria, a foliação gnáissica assume uma trama predominantemente vertical, gradando para a formação de protomilonitos e escassez de pegmatitos, os quais são restritos a diques e vênulas discordantes com a foliação principal. A trama milonítica é notadamente associada à transcorrência, formando zonas de cisalhamento locais de direções principais NNE-SSW.

A principal associação metamórfica observada corresponde a tectonitos lineo-planares, com ampla exposição de lineação de estiramento mineral suborizontal à horizontal, sempre associada a planos verticais. Já em cortes perpendiculares à foliação principal, ocorrem ainda boudins assimétricos de quartzo, granadas rotacionadas envoltas pelo traço da foliação, que pode formar estruturas do tipo S-C, marcando cinemática transcorrente sinistral. À medida que se avança na galeria, em torno de $90 \mathrm{~m}$ de extensão, é comum ainda o aparecimento de microdobras, e desenvolvimento de dobras do tipo chevron com kink-bands bem marcadas.

Entre os diversos corredores de cisalhamento formados, ocorrem regiões caracterizadas por uma forte migmatização. É comum nestas regiões a presença de estruturas estromáticas e diversos por flakes de biotita. Essas rochas apresentam contato brusco com os pegmatitos principalmente na parede do lado direito, que por sua vez apresentam bordas intensamente deformadas. As medidas gerais conferem à foliação gnáissica mergulhos em torno de

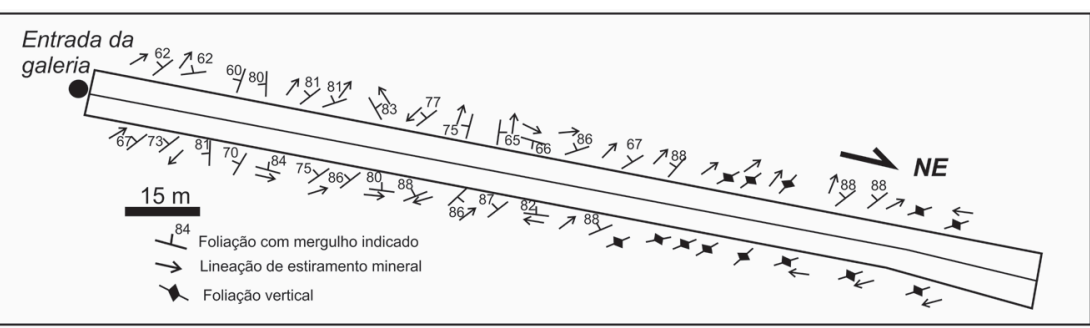

Figura 5. Medidas de estruturas planares e lineares obtidas na galeria de acesso da Mina Escola. Fonte: Autores 


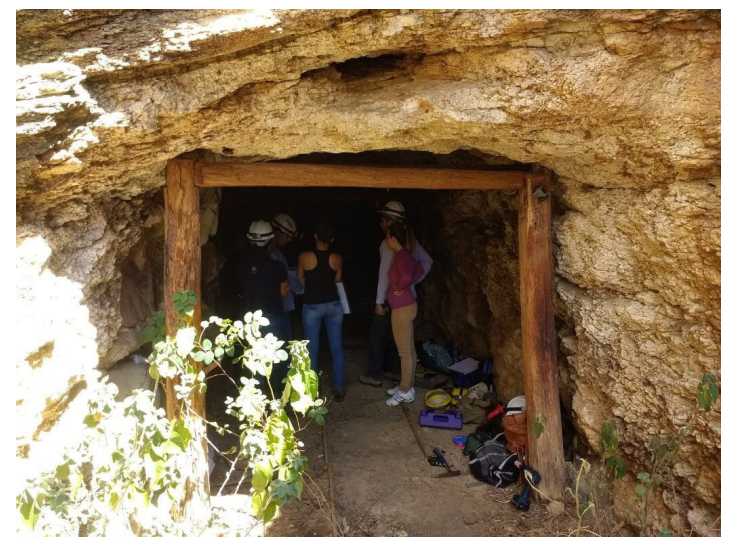

Figura 6. Entrada da galeria de acesso da Mina Escola. Fonte: Autores

padrões de dobramento, incluindo dobras que podem ser verticais, recumbentes ou reviradas, formando inclusive padrões em bainha (Figuras 7c e 7d). Dobras intrafoliais dos tipos S, Z e pitgmáticas, além de boudins assimétricos passam a ser os principais marcadores cinemáticos. Os migmatitos desenvolvem rochas com estruturas estromáticas, os quais englobam porções máficas com forte presença de granada (sugestivo de condições de alto grau metamórfico), além de minerais de alteração, incluindo clorita, o que possivelmente é resultado de alteração da biotita. Dentre estes litotipos, predominam membros metatexíticos com paleossomas bem desenvolvidos e restritos neossomas quartzo-feldspáticos. A presença de restitos máficos com anfibólio e piroxênio sugere, claramente, processos de anatexia in-situ. Essa trama é ainda caracterizada por ampla presença de dobras abertas e fechadas e foliação variável de médio a alto ângulo e de direções S12W, S18W, S27W e N36E, caracterizando uma sequência de corredores de cisalhamento com rejeito direcional (normalmente sinistrais) perpendiculares à extensão da galeria (Fig. 8a). Ocorrem localmente veios de pegmatitos discordantes com os padrões de dobramentos, inclusive deslocando alguns flancos dessas estruturas. Estas rochas apresentam caracteristicamente a presença de schorlita e minerais placoides, principalmente biotita (Fig. $8 b)$. A seção três, que cobre os $50 \mathrm{~m}$ finais da mina é particularmente importante, pois é marcada pela ocorrência de skarns, caracterizando o principal minério da mina, sendo a transição estéril-minério bem marcada em torno de $95 \mathrm{~m}$. Estas rochas
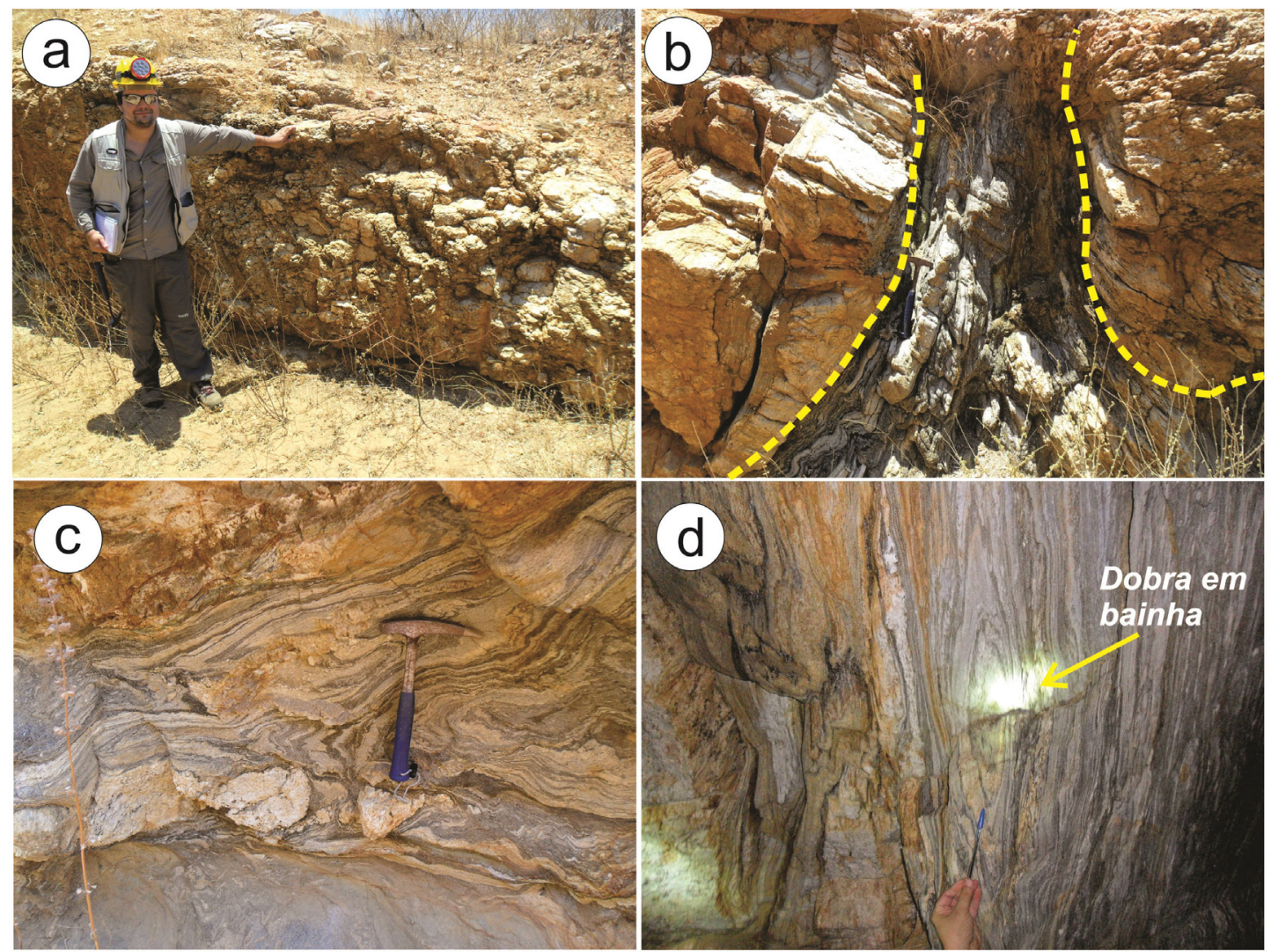

Figura 7. Aspectos geológicos da entrada da galeria de acesso. a) pegmatito homogêneo, b) contato entre pegmatito e gnaisse milonitizado, c) migmatito estromático a dobrado e d) detalhe de dobra em bainha observada em milonito vertical. Fonte: Autores 


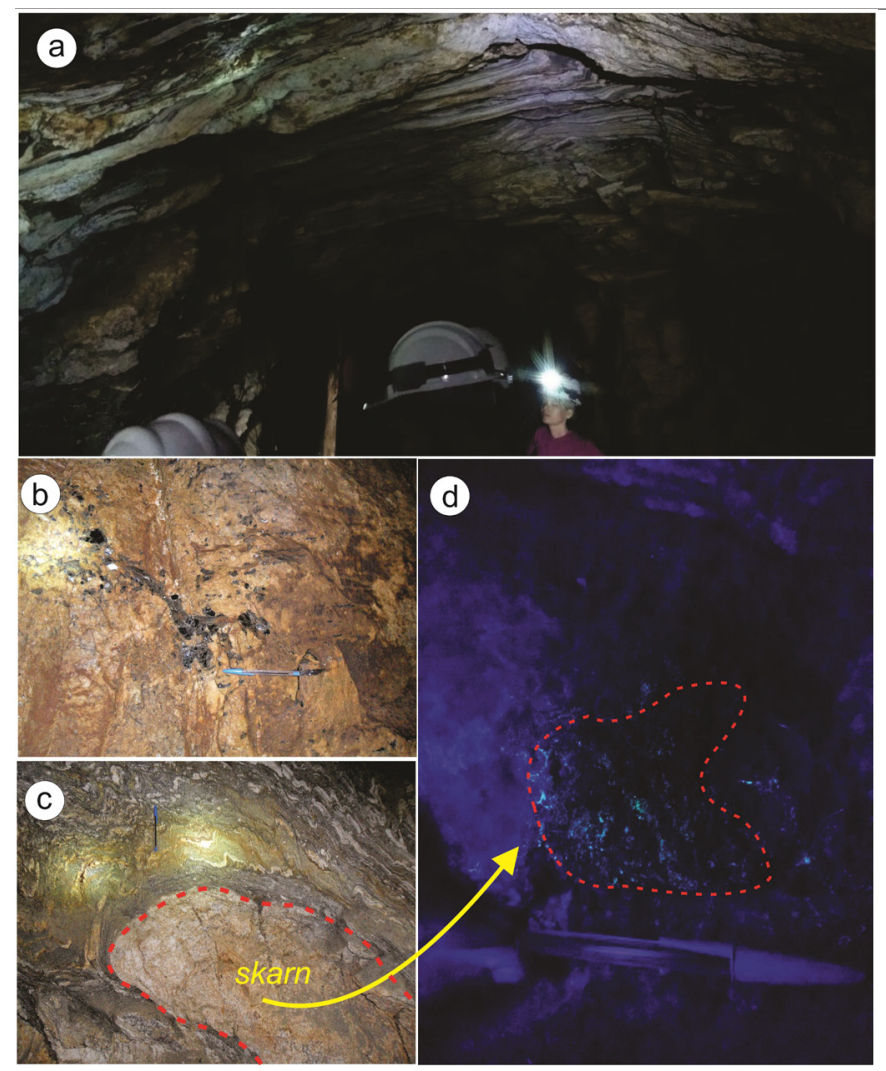

Figura 8. a) Região dominada por milonitos associados a zonas de cisalhamento transcorrentes e transversais à galeria de acesso; b) acumulação de turmalina do tipo schorlita em dique pegmatítico; c) bolsão de skarn circundado por migmatito hospedeiro; d) scheelita fluorescente em presença de mineral light. Fonte: Autores

ocorrem na forma de bolsões nas paredes da mina (Fig. 8c), sendo caracterizados pela presença de plagioclásio, diopsídio e granada (provavelmente do tipo grossulária). São ainda, por vezes deformadas e concentradas entre corredores de cisalhamento formando boudins, que podem ser simétricos ou assimétricos, indicando a importância do controle estrutural dúctil na formação dessas rochas. Aparentemente, o minério é do tipo compacto, sendo afetado por tectônica rúptil apenas nas suas bordas. Os cristais de scheelita desta mina podem ser facilmente identificados por meio de diversas propriedades físicas, incluindo a reação com $\mathrm{HCl}$ fervido, além de sua forte fluorescência, observada na presença do Mineral Light (Fig. 8d). Estimativa modal de campo sugere que este mineral represente pouco mais de $15 \%$ da moda da rocha.

\section{Considerações Finais}

Galerias subterrâneas correspondem a ambientes que fazem parte do dia a dia de geólogos, especialmente para a grande parcela que atua no ramo da mineração de curto prazo. Em função do alto custo de manutenção e relativo risco para estudantes de graduação, muitas vezes opta-se por visitar minas de empresas que encontram-se em plena atividade, o que torna inviável a prática acadêmica do mapeamento de galeria- A Mina-Escola da UFCG em Santa Luzia-PB, representa um laboratório didático para que estudantes de graduação vivenciem o trabalho em minas de pequeno porte, servindo assim para o desenvolvimento prático de diversas atividades cobrindo as áreas de lavra, beneficiamento de minérios e geologia de minas.

Este trabalho é o resultado do desenvolvimento de mapeamento geológico de detalhe realizado numa extensão de $200 \mathrm{~m}$ da galeria de acesso da Mina-Escola. A galeria, foi dividida em três seções o que permitiu observar uma ampla variedade litológica e mineralógica, abrangendo pegmatitos com a presença de minerais importantes do ponto de vista industrial como quartzo, feldspato, turmalina, e migmatitos que apresentam ampla variedade de estilos estruturais, permitindo o estudo de processos de deformação em várias escalas de observação. Além disso, ocorrem ainda milonitos que definem um regime dúctil, sendo caracterizados por muitos marcadores estruturais que podem ser observados em zonas de cisalhamento transcorrentes que cortam a galeria. Por fim, é possível ainda observar regiões com predisposição para ocorrência dos corpos mineralizados da Mina, que são bolsões e boudins enriquecidos em scheelita, bem como mapear áreas favoráveis ou desfavoráveis para a mineralização.

Espera-se por fim, que o trabalho desperte o interesse de instituições, docentes e estudantes que atuam na Região Nordeste, para a importância da Mina-Escola enquanto laboratório didático, disponível para o desenvolvimento de trabalhos de geologia/mineração.

\section{Agradecimentos}

Os autores agradecem aos funcionários da UFCG lotados na Mina-Escola, bem como ao Editor-Chefe de Revista Terrae Didática, Prof. Dr. Celso Dal Ré Carneiro (Unicamp). Agradecimentos adicionais são direcionados a José Fernando 
Pina Assis (UFPA) e a um revisor anônimo pelas críticas e sugestões.

\section{Referências}

Barreto S.B. 1999. Caracterização química, óptica e estrutural de turmalinas gemologicas dos pegmatitos Capoeiras, Quintos, Bulandeira e Batalha, Província Pegmatítica da Borborema. Espanha, Barcelona: Univ. Barcelona. 189p. (Tese de Doutorado).

Bermanec V., Horvat M., Zigovecki G.Z., Zebec V., Scholz R., Skoda R., Wegner R., Brito B.S.D., Dodony I. 2012. Pseudomorphs of low microcline after adularia fourlings from the Alto do Cabeça (Boqueirão) and Morro Redondo Pegmatites, Brazil. Can. Mineral., 50:975-987.

Beurlen H., Muller A., Silva D., Silva M.R.R.da. 2011. Petrogenetic significance of LA-ICP-MS trace-element data on quartz from the Borborema Pegmatite Province, northeast Brazil. Miner. Mag., 75:2703-2719.

Beurlen H., Thomas R., Silva M.R.R.da, Muller A., Rhede D., Soares D.R. 2014. Perspectives Li- and Ta-Mineralizations in the Borborema Pegmatite Province, NE Brazil: A review. J. South Am. Earth Sci., 56:110-127.

Brito-Neves B.B., Santos E.J., Van Schmus W.R. 2000.
Tectonic history of the Borborema Province. In: Cordani U.G., Milani E.J., Thomaz Filho A., Campos D.A. eds. 2000. Tectonic evolution of South America. Intern. Geol. Congr., p.151-182.

Ferreira J.A., 2011. Trilhas da Mineração no Seridó. Campina Grande, Sebrae. 236p.

Santos E.J., Medeiros V.C. 1999. Constraints from granitic plutonism on proterozoic crustal growh of the Transverse Zone, Borborema Province, NE-Brazil. Rev. Bras. Geoc., 29:73-84.

Santos E.J., Brito-Neves B.B., Van Schmus W.R., Oliveira R.G., Medeiros V.C. 2000. An overall view on the displaced terrane arrangement of the Borborema Province, NE Brazil. In: Intern. Geol. Congr., 31 ${ }^{\text {th }}$, Rio de Janeiro, Brazil. Proc. General Symposia. Tectonic Evolution of South American Platform, p.5-9.

Santos E.J., Ferreira C.A., Silva Junior J.M.F. 2002. Geologia e recursos minerais do Estado da Paraíba: Texto explicativo. Recife, CPRM: Serviço Geológico do Brasil.

Santos E.J., Souza Neto J.A., Silva M.R.R., Beurlen H., Cavalcanti J.A.D., Silva M.G., Costa A.F., Santos L.C.M.L., Santos R.B. 2014. Metalogênese das porções norte e central da Provícia Borborema. In: Silva M.G., Neto M.B.R., Jost H., Kuyumjian R.M. eds. 2014. Metalogênese das Províncias Tectônicas. CPRM, Belo Horizonte. p. 343-388.

Resumo: A Mina Escola representa um recurso didático localizada nas adjacências da cidade de Santa Luzia, Paraíba. Corresponde a um laboratório para estudos relacionados a mineração, em função dos seus componentes, tais como: mina subterrânea, escritório, alojamentos, maquinário para desenvolvimento de lavra e usina de beneficiamento. Adicionalmente, apresenta um forte potencial para a realização de atividades didáticas relacionadas a geologia, que não tem sido aproveitado até agora. Sua galeria de acesso compreende a 200m de mina subterrânea, que foi recentemente mapeada em detalhe. A galeria é caracterizada por amplo conteúdo litológico e mineralógico, abrangendo pegmatitos, migmatitos, milonitos e skarns, além de estruturas relacionadas aos regimes dúctil e rúptil. As lentes de skarn hospedam mineralizações de scheelita, que são facilmente identificadas com a utilização do mineral light e reação com HCL. A distribuição estéril-minério e a variedade de litotipos e estruturas observadas, fazem da Mina Escola um ambiente ideal para atividades didáticas de disciplinas como Geologia Econômica, Prospecção Mineral e Geologia Estrutural no NE do Brasil.

Palavras-Chave: Trabalho de campo, mina subterrânea, Estado da Paraíba. 